\title{
GINER DE LOS RÍOS: LA INSTITUCIÓN COMO ILUSTRACIÓN
}

\author{
ELÍAS DÍAZ \\ Universidad Autónoma de Madrid
}

\section{Resumen}

La vinculación de Giner de los Ríos al krausismo y a la Institución Libre de Enseñanza no significa una reclusión en ellos. Su propuesta, que hunde sus raíces en la Ilustración, es la cara optimista o positiva (tesis) del 98 (antítesis), cuya síntesis sería la generación del 14, más científica y política. El pensamiento de Giner no es un pensamiento neutro ni una suma ecléctica carente de originalidad, pero tampoco debe contaminarse de los dogmas de un partido político o un credo religioso. Lo fundamental en él es la conjunción de ciencia y conciencia: racionalismo armónico (frente a los argumentos de autoridad); Estado laico; filosofía social de carácter organicista, que concede protagonismo a la sociedad civil; filosofía política de sentido liberal radical; economía con intervención social; educación como instancia fundamental para la transformación social; razón ética frente a razón instrumental.

Palabras clave: Giner de los Ríos; krausismo; Institución Libre de Enseñanza; racionalismo armónico; razón ética.

\begin{abstract}
Giner de los Ríos was not confined to Krausism and the Institución Libre de Enseñanza. His proposal, rooted in the Enlightenment, is the optimist or positive side (thesis) of the '98 (antithesis), the synthesis of which would be the Generation of ' 14 , more scientific and political. Giner's thought is not a neutral thought nor an eclectic sum lacking in originality, but neither should it be contaminated by the dogmas of a political party or religious creed. Its fundamental point is the conjunction of science and consciousness: harmonic rationalism (opposed to arguments from authority); secular State; social philosophy with an organicist character, conceding protagonism to the civil society; political philosophy of a radical liberal sense; economy with social
\end{abstract}


intervention; education as a fundamental instance towards social transformation; ethical reason, as opposed to instrumental reason.

Keywords: Giner de los Ríos; krausism; Institución Libre de Enseñanza; harmonic rationalism; ethical reason.

El punto de partida, génesis y conexión de fondo, es sin duda la recepción por Julián Sanz del Río (1814-1868) de la filosofía del alemán Karl Ch. F. Krause (1781-1832), a través de los discípulos de este en el histórico viaje de aquel a Heidelberg en 1843. Recepción, pues, de la filosofía krausista en nuestro país, proseguida por Francisco Giner de los Ríos (1839-1915) y la Institución Libre de Enseñanza creada por él en 1876. Pero bien en claro la relevancia de lo anterior, yo, a mi vez, vengo insistiendo hoy en la necesaria interpretación para nuestros días de un Giner «no reducido ni recluido».

No reducido ni siquiera a la escuela filosófica del krausismo; no recluido ni siquiera en la casa madre del paseo del Obelisco. En el breve espacio de este artículo, yo querría suscitar algunas ideas, proponer algunas líneas de interpretación, en relación con Francisco Giner de los Ríos, sobre la base de lo que todos conocemos ya sobradamente acerca de su pensamiento, de sus actitudes intelectuales, políticas y sociales. Sobre esa base me propongo sugerir, como digo, algunas consideraciones que puedan añadir algo más a todo este acervo común de conocimientos ${ }^{1}$.

Querría así recuperar principalmente la perspectiva de un Francisco Giner germinal o seminal, mucho más que terminal. Sin alterar lo fundamental, todos sabemos que resaltar unas cosas u otras implica también entender a los clásicos de una u otra manera. Cada tiempo lee a los clásicos destacando ciertos aspectos o poniendo de manifiesto unas características preferentes y dejando otras más en segundo lugar. Hablo, pues, de un Giner de los Ríos germinal, seminal, y no terminal, porque quiero sobre todo transmitir la idea de que aquel no se termina, no se agota, en ese mundo filosófico que conocemos muy estrictamente como krausismo. Desde ahí, sin embargo, sus aportaciones e influencia personal, su simiente institucionista, sus ideas básicas, van a posibilitar después, a lo largo del

1. Para mejor explicación y ampliación de estas páginas conmemorativas del centenario de la muerte de Giner, reenviaría a dos libros míos: uno, de 1973, La filosofía social del krausismo español (última ed., Madrid, Debate, 1989); otro, muy reciente, titulado De la Institución a la Constitución. Política y cultura en la España del siglo XX (Madrid, Trotta, 2009). 
siglo Xx y para nuestro tiempo también, el desarrollo en España con otra serie de direcciones intelectuales (positivismo, neokantismo, socialismo humanista) de algún modo derivadas germinalmente de aquel. La suya es una actitud, por tanto, germinal, origen de cosas nuevas que encontrarán amplia acogida social. Su pensamiento no va a significar un cierre, una terminación, el final del krausismo en el momento de su muerte, sino, a partir de ahí, un impulso renovador que va a desarrollarse críticamente, abiertamente, a lo largo del complejo y difícil siglo xx. Lo que quiero, en definitiva, resaltar es que Giner no es solo (ni principalmente) el último krausista, sino sobre todo el comienzo, con la Institución, de un decisivo renacimiento intelectual, científico y filosófico, de nuestro país.

Me detendré solo un momento en su recíproca influencia con el 98. En un esquema no distorsionante, creo, se podría decir que las posiciones del krausismo y la Institución Libre de Enseñanza representan el momento de la afirmación en el ámbito del pensamiento, la afirmación de la filosofía, el momento de la tesis, si se quiere. La generación del 98 sería en cierto modo el momento de la antítesis, de la duda, incluso de la negación, de la negatividad. La relación 98-Institución no es para nada una relación de continuidad sin más, lineal, sino una relación de oposición, de antítesis; pero la negación necesita siempre la afirmación previa - y esta de aquella- para poder avanzar y dar lugar a algún tipo de síntesis posterior. Están Giner y Unamuno en el mismo mundo, el de la modernidad, pero uno lo vive desde la armonía y otro desde la agonía.

En una reconstrucción un tanto demasiado resumida del pensamiento español del siglo Xx, señalaría, pues, que lo que representan Giner y la Institución es precisamente esa afirmación de una filosofía que enlaza directamente con la Ilustración. Atreverse a saber, atreverse a pensar libremente, hacer uso público de la propia razón. La Institución fue la Ilustración en España; una recepción tardía de la Ilustración, lo cual implicaba a su vez inconvenientes (patologías) y ventajas (conciencia del límite, mayor sentido histórico). Todo ello no era, por supuesto, algo privativo o exclusivo de España. Pero la recepción de la Ilustración no se realiza solo a través de la Institución. Lo que significa en España la generación del 98, el momento de la negatividad, es algo (¿Nietzsche, Freud?) que se produce en toda Europa en el fin de siglo. En este esquema, diría, con evidente abuso de la dialéctica (y de Hegel), que la generación del 14 y sus derivaciones podrían significar de alguna forma la síntesis de aquella afirmación y aquella negación. 
Ya sé que todo esto necesitaría muchas más precisiones de fondo y de detalle: y asumirlo, además, con espíritu crítico, y no dogmático. Pero pienso que puede ser útil para el debate esta perspectiva dialéctica del pensamiento español, de la filosofía española del siglo Xx, en la cual la negación fin de siglo se hace sobre la afirmación institucionista, y la síntesis viene representada por la generación del 14, más científica y política. Esta - recuérdese- también deriva directamente, pero a través de este proceso de negación y de afirmación, de los hombres que, gracias a la Junta para Ampliación de Estudios, han salido afuera a ampliar sus estudios y regresan a España en torno a estos años. La generación del 14, por lo tanto, Ortega y todo el grupo plural congregado en torno a la revista España, los que están tras la Liga para la Educación Política y todo lo que viene después, la generación del 27, la generación de la República, los socialistas como Besteiro o Fernando de los Ríos, son, de esa manera compleja y dialéctica, un derivado de Giner y del pensamiento ilustrado de la Institución. Pero - hago observar otra vez- nada de esto hubiera podido salir, ni explicarse, solo desde la influencia de Krause y del krausismo alemán. Hay también mucho del mejor Kant en las tareas y creaciones de la Institución.

Pero vendría en seguida la guerra (in)civil y la condena por el fascismo católico de los «sin patria y sin dios» de la nefanda Institución. Hubo después que recuperar todo esto, a partir de los años cincuenta y sesenta, fundamentalmente. El resto, hasta hoy, es ya nuestra historia, quiero decir la de las generaciones de los jóvenes del 56 y del 68 frente al franquismo para llegar a 1978. Sin forzar esas líneas críticas y dialécticas de nuestra reciente historia, me parece, no obstante, que desde ahí y andando el tiempo puede establecerse también en nuestros días un nexo claro entre Institución y Constitución. Yo he hablado, en este sentido, y en más de una ocasión, de un siglo de pensamiento liberal y democrático en España, en resistencia ante la persecución, comprendiendo ese largo y difícil tiempo que va desde 1876 a 1978 bajo el arco común de la Institución a la Constitución.

Esta perspectiva germinal, y no terminal, en la que estoy situando aquí mi interpretación implica también entender a Giner de los Ríos como no recluido ni reducido. Al decir «no recluido» quiero decir no recluido tampoco en el ámbito habitacional, a veces un poco estricto o estrecho, de la propia Institución Libre de Enseñanza. Hay, ha habido, un cierto regusto de un punto de vista interiorista que en vida ve a Giner de los Ríos (los que no somos institucionistas por herencia y tradición siempre lo sentimos así, como un tanto empequeñecido) según esa imagen doméstica de 
reclusión en esa casa, en la casa del paseo del Obelisco, hoy del General Martínez Campos, con don Manuel Bartolomé Cossío, con don Ricardo Rubio, rodeado en todo momento por las familias de unos y otros... Me parece bien, pero — icorríjanme los viejos institucionistas cuando les parezca oportuno! - creo que con ello se facilita una visión de Giner y de la Institución, como digo, excesivamente doméstica y recluida entre esos muros, en esa casa, lo cual impone también unos usos, unas rutinas, un cierto tipo de relaciones, hasta prejuicios y manías, con celos y enfrentamientos personales no precisamente muy atrayentes.

Me parece que esa reclusión no es buena ni verdadera. Pero, de hecho, alguna de las últimas biografías que se han escrito sobre Giner de los Ríos - una en concreto, diría yo, en verdad infame, con intencionada y total distorsión de su personalidad y su pensamiento- se ceba injustamente e incide con total exceso en esa perspectiva interiorista, en esa perspectiva de reclusión elitista, de grupo cerrado y sectario. Creo que todo ello empobrece gravemente el talante, la actitud personal y la amplitud social de los proyectos de aquel y del pensamiento mismo de la Institución. Más que la reclusión, lo que habría que destacar como fundamental y más cierto de su obra es - creo- la perspectiva de extensión. Recordemos justamente la famosa Extensión Universitaria y su acercamiento al pueblo con muy válidas propuestas de reforma. Y lo mismo en el campo del pensamiento: no una escuela cerrada en sí misma, sino abierta a las otras corrientes de la filosofía europea y española en el siglo Xx. Influye y es influida por lo mejor de esas filosofías, y con su recuperación tras los tiempos de persecución y silencio, asumiendo toda esa ilustrada tradición y la que está también presente en la obra de los exiliados republicanos, va a repercutir en el interior con buenas inspiraciones y aportaciones a la Constitución, que es tanto como decir, con todos sus problemas, a la democracia española actual.

Señalo, pues, que desde esa perspectiva germinal, no terminal, junto a ese Giner de los Ríos no recluido, hay también, decía, un Giner «no reducido». ¿No reducido a qué? Pues —esto es lo principal aquí- no reducido ni siquiera al krausismo. Como se sabe, «krausismo» fue el mote, el rótulo que, tras la recepción y difusión de Krause hecha por Sanz del Río, precisamente más utilizaron los adversarios integristas y ultramontanos para denominar e intentar denigrar, por foránea y extraña, esta filosofía. Por supuesto que nadie podría decir que Giner y los primeros institucionistas no fueron krausistas y que no tuvieron mucho que ver con Krause; eso, comparativamente, era hasta muy positivo. Pero yo insistiría, a mi 
vez, en que su amplio desarrollo y extensión posterior en nuestro país no se pueden reducir a ello. Por otro lado, asistimos hoy a una recuperación (incluso en Alemania) de Krause, mucho más importante de lo que se dijo en su tiempo y de lo que Menéndez Pelayo, que no lo conocía, dejó ya sentenciado como verdad dogmática. Reconociendo, pues, el pensamiento de Krause como base de esa filosofía, sobre todo en Sanz del Río, pero asimismo en Giner, aunque ya con otras influencias y exigencias, me parece - como digo- que no puede entenderse el reconocimiento de Giner y de las creaciones institucionistas (Junta para Ampliación de Estudios, Residencia de Estudiantes y tantas otras obras científicas y culturales hasta los años de la República) como si hubiesen sido producto de una mera aplicación de las ideas krausistas, de la filosofía de Krause. Es preciso, en consecuencia, no reducir absolutamente el hispánico institucionismo al germánico krausismo. En esa vía reencontramos entonces a un Giner germinal, no terminal, un Giner no recluido, no reducido: y con eso - creo- recuperamos al mejor Giner de los Ríos.

Tenemos buena base para ello. Recordemos un muy fundamental artículo de los Estatutos de la ILE que todos conocemos y que hemos leído con frecuencia, pero sobre cuyo fondo creo que no siempre se obtienen las adecuadas conclusiones. Decía así el artículo 15: «Esta Institución es completamente ajena a todo espíritu o interés de comunión religiosa, escuela filosófica o partido político». Por de pronto, completamente ajena a todo espíritu o interés de comunión religiosa: es decir, no se identifica la ILE con una religión, lo que defiende es el pluralismo religioso, la libertad de interpretación de la religión, incluso la posibilidad de su negación. Es decir, el mejor laicismo. Tampoco se identifica —ni se reduce, vengo subrayando aquí- con una escuela filosófica, ni siquiera, pues, con el krausismo, declaración de la cual habría que sacar las debidas consecuencias. Y obviamente la ILE no es un partido político. ¿Significa esto - como a veces extrañamente se ha querido interpretar- que Giner y la Institución tendrían un ideado, una concepción del mundo, sin implicaciones de ninguna escuela filosófica, de ninguna religión, de ningún partido político? En modo alguno cabe tal absurdo. ¿Sería un pensamiento neutro o, si se prefiere, completamente adiáforo, neutralista? Yo tampoco lo veo así en el sentido, sin más, de mero eclecticismo o, peor aún, de indiferencia respecto de valores éticos, políticos, intelectuales. De lo que se trata es de una filosofía que no es de una escuela, que no es de un partido, que no es de una comunión religiosa. Se señala allí, en la segunda parte de ese mismo 
artículo quince, que lo fundamental es la conciencia crítica y la ciencia, es decir, ciencia y conciencia: esto es, otra vez la Ilustración.

Me parece que aquí, en la conexión Ilustración-Institución, radica la base para entender mejor a Giner y para desvincularlo de esas y otras adscripciones dogmáticas y unilaterales. Pero nunca hay indiferencia neutral. Siempre que oigo hablar de neutralismo y neutralidad, me acuerdo de aquello de Unamuno cuando le interpelaban: «Don Miguel, usted en la próxima guerra civil será neutral, viendo cómo está criticando a unos y a otros». Y contestaba aquel: «No, no, jamás, yo no soy nunca neutral, porque neutral es neuter, ni con unos ni con otros»; es decir — añado yo-, con nadie, salvo con uno mismo. «Seré si acaso alterutral», añadía Unamuno, es decir, con unos y con otros, uniéndolos, fundiéndolos y confundiéndolos incluso. En alguno de mis libros me he ocupado más detenidamente de estas cuestiones y también de la no confusión, en el tema de la objetividad (mejor que de la neutralidad), entre las weberianas «referencia a valores» (Wertbeziehung) y «liberación de los juicios de valor» (Wertfreiheit). La referencia a valores es ineludible (ninguna realidad es adiáfora, valorativamente neutra, indiferente); pero hay que librarse de los juicios de valor que deforman u ocultan el conocimiento de la realidad. Me parece que esa filosofía de la Ilustración-Institución fue, y sigue siendo, buena guía para los mejores planteamientos y orientaciones del pensamiento español, que tiene a Francisco Giner de los Ríos como referente imprescindible.

¿Cómo especificar los principales caracteres de ese pensamiento? Casi telegráficamente, para terminar, pero reasumiendo todo lo anterior, cabe - creo- decir que lo que Giner de los Ríos y la Institución aportan al acervo común crítico de todo ese pensamiento español podría concretarse en los siguientes puntos (ya enumerados y desarrollados más detenidamente en esas publicaciones mías ya mencionadas aquí):

a. Una filosofía que ellos, desde Sanz del Río y el propio Giner, denominan racionalismo armónico: es decir, el reconocimiento de la razón frente a los argumentos de autoridad de la escolástica impuesta casi desde siempre en nuestro país, así como durante todo aquel tiempo y otra vez, con la guerra civil, hasta mucho después. Racionalismo armónico significa razón y experiencia, razón e historia, razón teórica y razón práctica... Me permitiría decir que aquí, además de Krause, hay también o casi más de Kant.

b. Una actitud religiosa — dejemos ahora al margen el famoso panenteísmo- de afirmación de la conciencia crítica, de la libertad 
religiosa, de un cristianismo racional o incluso de agnosticismo, siempre que todo ello sea asumido de buena fe y con buena conciencia. Es decir, un Estado laico.

c. Una filosofía social de carácter organicista — por tanto, no individualista, pero tampoco colectivista-, que ve la sociedad, el grupo social, como compuesto por asociaciones intermedias plurales. Puede señalarse que en esta filosofía social —no cité antes la conexión con la Constitución en vano- hay base para un entendimiento de la sociedad políticamente organizada en una situación cercana a lo que sería hoy en España el Estado de las autonomías e, incluso, un Estado federal. También debe haber base para la inclusión de los movimientos sociales, que articulan pluralmente en nuestro tiempo el conjunto de la sociedad civil.

d. Una filosofía política de sentido liberal radical. Como se ve, soy partidario de recuperar el término «radical». Nada que ver con su uso, como ocurre actualmente, como sinónimo de extremista o, incluso, de violento o terrorista. El autor de la biografía infame a la que me he referido antes cifra siempre su condena — «Giner es un radical»- en lo que para él constituye el peor de los males. Sí, yo creo que es un liberal radical, en el sentido de que va al fondo de lo que es la filosofía liberal, a sus raíces, que implican y exigen coherentemente una actitud democrática de verdad, la libertad para todos. Por eso diría que, aunque Giner — a finales del XIX - no es partidario explícitamente del sufragio universal, porque cree que no se dan todavía las condiciones para ello (su propuesta educativa general subsanaría con el tiempo esa deficiencia, piensa él), sin embargo, me parece que en ese liberalismo radical están potencialmente las bases de un liberalismo democrático que podría ir incluso bastante más allá (por ejemplo, la socialdemocracia de institucionistas como un Julián Besteiro o un Fernando de los Ríos). Se trata en todo caso de una filosofía política de, por lo tanto, oposición clara y rotunda a todo tipo de absolutismos, a todo tipo de dictaduras y totalitarismos, a todo tipo de tradicionalismo. Giner de los Ríos, como filósofo del derecho, es un hombre que postula expresamente a principios del siglo Xx un Estado de Derecho entendido ya como un Estado social de Derecho, y que además - y esto, digámoslo, sí que proviene más de Krause que de Kant- reclama, en consecuencia, los derechos sociales, los derechos de la mujer, los derechos del medio ambiente, de la ecología, 
de la paz, de la atención preferente a los niños, a los ancianos... Es decir, los derechos fundamentales que constituyen la base en nuestro tiempo del Estado social y democrático de Derecho. Dejemos esto apuntado aquí, como referencia, una vez más, a su presencia, junto a esas otras derivaciones democráticas, en la Constitución de 1978.

e. ¿Cuál y cómo es en esa concepción la función de la economía? Desde luego, no lo es el abstencionismo estatal y social que a veces se quiere unir inescindiblemente al pensamiento ilustrado. El laissez faire, laissez passer del liberalismo económico no es la respuesta en la perspectiva liberal radical (ética) de Giner y de la filosofía política de la Institución. Se propugna más propiamente un intervencionismo social, pero, por supuesto —y está bien—, nunca un exclusivo y excluyente intervencionismo estatal. Su intervencionismo público, social y estatal, con sector privado también, se ha visto asimismo como una vía de aproximación al socialismo democrático: eso será ya obra, como señalé, de Fernando de los Ríos o de Julián Besteiro, que tampoco son estatalistas, pero desde luego sí deja claro Giner que el liberalismo económico — hoy diríamos el «liberismo», paleoliberalismo o neoliberalismo conservador (neocon) — no es para nada lo más concorde con su pensamiento.

f. La ética y la educación como instancias más radicales para la transformación social. Se puede avanzar hacia ella a través del derecho, la política, la economía, es cierto, y más aún con la cultura, con la ciencia, con la moral de la ciencia, con el acercamiento a la ciencia europea... Pero todas esas dimensiones habrán de ser entendidas (no reducidas) no desde una razón instrumental (de medios), sino, otra vez la Ilustración, desde una razón de fines, una razón ética. Si, en consecuencia, falta la ética, y si falta la educación en sus valores fundamentales, los cambios lo serán solo en la superficie de las cosas. El resorte más radical de este ideario de Giner de los Ríos que he resumido aquí muy sucintamente es, pues, la ética y la educación. Formar hombres, caracteres, criterios: esa será su propuesta pedagógica en la ILE y en sus otros centros de educación. El saber y la virtud, la ética unida al conocimiento, teoría y práctica, ciencia y conciencia son la base de ese pensamiento. A ello dedicó su vida. Querría, en ese sentido, terminar recordando unas palabras de Giner, cuando en 1899, el año siguiente al Desastre, todo el mundo está debatiendo sobre qué hacer en este país 
después del 98. Habla así: «En los días críticos en que se acentúan el tedio, la vergüenza, el remordimiento de esta vida actual de las clases directoras, es más cómodo para muchos pedir alborotados a gritos una revolución, un gobierno, un hombre, cualquier cosa, que dar en voz baja el alma entera para contribuir a crear lo único que nos hace falta: un pueblo adulto».

Pienso que desde entonces, a pesar de todas las interrupciones y obstáculos que la historia (es decir, nosotros, los hombres y las mujeres) desgraciadamente hemos introducido en este proceso, resulta posible constatar que a la acción y al pensamiento de Giner de los Ríos y de todos quienes participaron en las diferentes instituciones y organismos derivados de la Institución Libre de Enseñanza se les debe reconocer en justicia la destacada aportación que han llevado a cabo para lograr que este país haya formado, diría yo (si no antropológicamente optimista, espero que algo realista), un pueblo relativamente adulto. $\mathrm{Y}$ al decir pueblo incluyo a todos. Las tareas presentes y futuras que tenemos ante nosotros serán la mejor medida y comprobación de la validez de este aserto que sigue siendo también para mí una muy firme esperanza. Incluso a la altura de este difícil año de 2015 en que conmemoramos, recordando siempre el poema de Antonio Machado, el centenario de su muerte.

Fecha de recepción: 22-4-2015

Fecha de aceptación: 12-10-2015 